\title{
A Comparative Study of Aggressive Among the Sports Person of Different Semi - Content Games
}

\author{
Mahesh Kumar \\ C.R.M. Jat. College, Hisar (Haryana)
}

\begin{abstract}
A$ study was conducted with an objective to find out the aggression level among the sportsperson of semi-contact games. $A$ total number of 200 (100 male and 100 female) players of semi-contact games like Basketball, Handball, Kho-Kho and Football of Haryana state who participated at national and Inter University level were contacted to collect the information. It was found that in over all male sportspersons of semi-contact games having more aggressive tendency as compare to their female players. It was also discovered that the aggression level of Basketball players was found higher as compare to the players of Handball, Kho-Kho and Football games
\end{abstract}

Keywords: Aggressiveness, Sportsperson, Basketball, Handball, Kho-Kho and Football

\section{Introduction}

Sports have become the head line news not only at the local level but at the international level even in the electronic media. Winning of medals, prizes and rewards at the international level has become prestigious issue for the nation as well as for an individual. Without second though every individual can feel the magnitude of importance of sports at hearts now a days.

Top performances no longer occur at random or as a result of chance alone. International performances in various sports and games are influenced by many factors, such as physical, physiological, psychological, nutrition, technique, tactics, physique and body compositions etc. Now a days competition are so tough that even a very small factor plays an influencing role in achieving position in international competition.

Psychology in sport is a broad church. It focuses on all the factors affecting participation and performance in sport, and applied sports psychology, which focuses purely on applying psychology to enhance athletic performance (Cox, 2011).

\section{Aggression and sports}

Sports involves physical confrontation between individuals and makes a good platform for the occurrence of aggressive acts. However, "Aggression in sport is not perceived as unequivocally negative; when it is an assertive behaviour as searching for the source, aggression in highly desirable" (Wlaglo et al., 2007). The aggression as defined as, "The attempt to injure characterized by the inner desire to win an advantage or received a reward" (Baired, 2009).

Silva (1983) and Bredemeiner (1986) concluded that, "Engaging in aggressive sports could increase the aggressive behaviour" (Keeler, 2007). At the same time Vigt (1982) has tudied many type of sports in context to he number of committed offenses, he concluded that aggressiveness is normally linked with contact sports (Munoz, 2002).
Kerr (2008) studied that aggression in sports cannot automatically be guesed as either aggressive or non aggressive but it is the athlete's intention that indicates the acceptability of an action. The legitimacy and acceptability of aggressive behaviour, which is related to particular rules and norms of the sport, are recognized as pertinent in defining and classifying aggression in sport (Maxwell and Mooores, 2007).

\section{Aggression and Sports Performance}

In relation to the effect of aggression on sportsman's performance, different empirical studies show conflicting results in different sports Wright (2009) and Zitek and Jordon (2011) in basketball, Russell (1974) and McGrathy and Kelly (1978), Andreevs (1974), Wankel (1973) in Ice Hockey had concluded positive relationship between aggressive actions and number of victories. However, Albrecht (1979) in Handball, Hanegby and Tenenbabum (2001) in Tennis found the aggressiveness had a negative impact on the sports performance.

Now a days sports psychologist have been empress on the aggressive behaviour of the sports persons in he field and event out of the field. During intense competition a sportsman undergo many important behavioural changes like aggression, anxiety, anger, intelligence and adjustment of themselves as per the situation during the competition. Keeping the above facts in view the emphasis has been given to study aggressive behaviour of sportsperson in different semi- contact games like Basketball, Handball ,Kho-Kho and Football. The present study was conducted with the following objectives.

1) To find out whether there was any difference in Aggressions level among the sports persons of different semi- constant games.

2) To find out whether there was any difference in Aggressions level between male and female players of different semi- contact games.

\section{Materials and Methods}

\section{Sampling}

In the present study, multistage sampling plan in which 


\section{International Journal of Science and Research (IJSR) \\ ISSN (Online): 2319-7064 \\ Index Copernicus Value (2015): 78.96 | Impact Factor (2015): 6.391}

stratified random sampling technique and simple random sampling technique were used for selecting the samples. The present investigation was conducted on a total of 200 sportspersons of Haryana State, who had participated at National and Inter University level tournaments in semicontact games like Basketball, Handball ,Kho-Kho and Football. The subjects were in the age group of 18-25 years. This group was further divided into two sub-categories having 100 males and 100 females each.

The selection of tools was governed by the consideration of their (i) availability (ii) suitability to the sample (iii) reliability and validity. Keeping in view these consideration, "Aggression Questionnaire" (Pati, 1976) have been used for measuring aggressive behaviour.

\section{Collection of data and administration of tests}

In order to collect the requisite data sampled the entire population and decided the appropriate tools to measure the attributes concerned and finally to administer tools on the sample were selected. The requisite data was then collected and filled in prescribed questionnaires. After selecting the sample of the study and before conducting the tests, the purpose of testing and technique to be employed in the study of the subjects and all possible doubts were cleared. In this study questionnaire method was used. The questionnaire was administered to all the subjects in accordance with the instructions laid down in the manual and under the direct supervision of the investigator.

\section{Statistical procedures}

Keeping in view, the objectives as well as design of the study, the appropriate statistical techniques were used to analyse the data.

\section{Aggression semi-contact}

Table 1: Analysis of variance for the data on aggression in semi-contact games

\begin{tabular}{|l|c|c|c|c|}
\hline Source & D.F. & S.S. & M.S. & F-ratio \\
\hline Sex & 1 & 37483.22 & 37483.22 & $9.03^{* *}$ \\
Semi-contact games & 3 & 85673.72 & 28557.91 & $6.88^{* *}$ \\
Interaction & 3 & 7826.50 & 2608.83 & 0.63 \\
Error & 192 & 797079.84 & 4151.46 & \\
\hline Total & 199 & 97924.96 & & \\
\hline
\end{tabular}

**significant at 0.01 level, $*$ Significant at 0.05 level

$\mathrm{F}_{0.1}(1,192)=6.76, \mathrm{~F}_{0.5}(1,192)=3.89, \mathrm{~F}_{0.1}(3,192)=3.88$, $\mathrm{F}_{0.5}(3,192)=2.65$

Table 1 reveals that F-ratio (9.03) of aggressive tendency in semi-contact games for sex is more than the table value of $\mathrm{F}$ (6.76) with (1.192) d.f. at 0.01 level. It shows that there is a significant difference in aggression among the sportsmen and sportswomen of semi-contact games.

From Table 1, it can be inferred that F-ratio (6.88) of aggressive tendency in semi-contact games is more than the table value of F (3.88) with (3.192) d.f. at 0.01 level. It shows that there is a very high significant difference in aggression among the players of different semi-contact games.

Tale 1 shows that F-ratio (0.63) of aggressive behaviour in semi-contact games for interaction is less than the table value of F (2.65) with (3.192) d.f. at 0.05 level. It shows that there is no significant difference in interaction $(\mathrm{Sex} \times \mathrm{Semi}-$ contact games) of different sports group in semi-contact game players.

Table 2: Mean scores on aggression for male and female players in semi-contact games (sports combined)

\begin{tabular}{|c|c|c|}
\hline Female & Male & C.D. \\
\hline 51.42 & 490.37 & 17.85 \\
\hline
\end{tabular}

From Table 2 it can be seen that in semi-contact game the mean difference of male and female on aggression data is more than the critical difference. Than it may be concluded that the aggression level of male players is higher than that of female players at 0.05 level.

Table 3: Mean scores on aggression in different semicontact games (male and female players combined)

\begin{tabular}{|l|c|c|c|c|}
\hline Basketball & Handball & Kho-Kho & Football & C.D. \\
\hline 539.02 & 499.72 & 490.10 & 487.40 & 25.25 \\
\hline
\end{tabular}

Table 3 shows that in aggressive tendency of behaviour of semi-contact game the mean values of Handball, Kho-Kho and Football players have no significant difference between them. But the mean value of Basketball players is significantly higher as compare to the mean values of Handball, Kho-Kho and Football players. So, it shows that the aggression level of basketball players is higher as compare to the players of Handball, Kho-Kho and Football games.

Table 4: Mean scores on aggression for male and female players of semi-contact games

\begin{tabular}{|c|c|c|c|c|c|}
\hline & Kho-Kho & Handball & Basketball & Football & C.D. \\
\hline Male & 539.02 & 509.28 & 548.72 & 511.88 & 35.71 \\
\hline Female & 479.08 & 490.16 & 529.32 & 462.92 & \\
\hline
\end{tabular}

Table 4 reveals that mean scores of aggressive tendency in male players of Kho-Kho, Handball and Basketball have no significant difference as compare to their female players in their respective games. Therefore the aggression level of male and female players of these games are equal.

It also indicates that the mean value of aggression in Football male (511.88) players is significantly higher than the mean value of their female (462.92) players. So, it shows that the football male players are more aggressive than their female players.

From Table 4, it is also concluded that the Basketball game players in both male and female section are having high aggressive tendency as compare to Handball, Kho-Kho and Football players.

\section{Conclusion}

It was found that in over all male sportspersons of semicontact games having more aggressive tendency as compare to their female players. It was also discovered that the aggression level of Basketball players was found higher as compare to the players of Handball, Kho-Kho and Football games. Female players of Kho-Kho, Handball and 
Basketball were found equally aggressive when compare with the made players of their respective game. But male Football players were found more aggressive than their female players.

\section{References}

[1] Albrecht, D. (1979). Zur sportartspezifischen aggression im wettkapfspiel. Sportwissenshaft, 9: 78-91.

[2] Baird, S.M. (2009). Mean(ing) to me: a symbolic interactionist approach to aggression in sport psychology. Quest, 61(4): 377-396.

[3] Cox, R. (2001). Sport Psychology. New York, McGraw-Hill.

[4] Hanegby, R. and Tenenbaum, G. (2001). Blame it on the racket: Norm-breaking behaviours among junior tennis players. Psychology of Sport and exercise, 2 : 117-134.

[5] Keeler, L. (2007). The differences in sport aggression, life aggression and life assertion among adult male and female collision, contact and non-contact sport athletes. Retrieved from http://www.oregonpdf.org/pdf/PSY2213Keeler(151).pdf

[6] Kerr, J.H. (2008). A critique of the development of the Competitive Aggressiveness and Anger Scale. Psychology of Sport and Exercise, 9: 721-728.

[7] Maxwell, J.P. and Moores, E. (2007). The development of a short scale measuring aggressiveness and anger in competitive athletes. Psychology of Sport and Exercise, 8: 179-193.

[8] Munoz, A.P. (2002). Conducta agresiva y deporte [Aggressive behavior and sport]. Cuadernos de Psicologia del Deporte, 2(1): 39-56.Retrieved from http://revistas.um.es/cpd/article/ view/105021

[9] Pati, G.C. (1976). “Aggression Questionnaire”, Cuttak Rupa Psychological Center Varanasi.

[10] Russell, G.W. (1974). Machiavellianism, locus of control, aggression, performance and precautionary behavior in ice hockey. Human Relations, 27 : 825-837.

[11] Silva, J.V. (1983). "Normative compliance and rule violating behaviour in sports". International Journal of Sport Psychology, 12:10-18.

[12] Wankel, L.M. (1973). An examination of illegal aggression in inter-collegiate hockey. In Villiams, I.D., and Wankel, L.M. (Eds.): Proceedings of the Fourth Canadian Psycho-Motor Learning and sports Psychology Symposium (531-542). Ottawa: National Health and Welfare.

[13] Wlazlo, A., Szuszkiewicz, M. and Wlazlo, E. (2007). Self-aggression in athletes practicing combat sports Physical Education and Sport Magazine. Retrieved from http://www. scribd.com/doc/62640986/Sefaggression-in-athletes-practicing-combat-sports

[14] Wright, M.A. (2009). The relationship between teamlevel aggression and basketball performance. Master Thesis. The Georgia Institute of Technology: Atlanta.

[15]Zitek, E.M. and Jordan, A.H. (2011). Anger, aggression, and athletics: Technical fouls predict performance outcomes in the NBA. Athletic Insight, $3: 29-39$. 